\title{
Mismatch Repair Endonuclease PMS2
}

National Cancer Institute

\section{Source}

National Cancer Institute. Mismatch Repair Endonuclease PMS2. NCI Thesaurus. Code C21479.

Mismatch repair endonuclease PMS2 (862 aa, 96 kDa) is encoded by the human PMS2 gene. This protein plays a role in DNA mismatch repair. 